\title{
IR panoramic alerting sensor concepts and applications
}

\author{
Arie N. de Jong, Piet B.W. Schwering \\ TNO - Physics and Electronics Laboratory, The Hague - Netherlands
}

\begin{abstract}
During the last decade, protection of military and civilian operational platforms against weapons like guns, grenades, missiles, Unmanned Combat Aerial (and surface) Vehicles (UCAV's) and mines, has been an issue of increased importance due to the improved kill-probability of these threats. The standard countermeasure package of armour, guns, decoys, jammers, camouflage nets and smokes is inadequate when not accompanied by a suitable sensor package, primarily consisting of an alerting device, triggering consecutive steps in the countermeasure-chain. In this process of alert four different detection techniques are considered: pre-alert, giving the directions of possible attack, detection of an action of attack, identification of the threat and finally the precise localisation (3-D). The design of the alerting device is greatly depending on the platform, on which it will be used, the associated and affordable cost and the nature of the threat. A number of sensor packages, considered, developed and evaluated at TNO-FEL is presented for simple, medium size and large and expensive platforms. In recent years the requirements for these sensors have become more and more stringent due to the growing number of scenarios. The attack can practically be from any direction, implying the need for a large Field of Regard (FOR), the attack range can vary considerably and the type of threat can be very diverse, implying great flexibility and dynamic range and rapid response of the sensor. Especially the localisation at short ranges is a challenging issue. Various configurations including advantages and drawbacks are discussed.
\end{abstract}

Keywords: Infrared, IRST, alerting devices, panoramic surveillance, survivability

\section{INTRODUCTION, REVIEW OF CONCEPTS}

The protection of military and civilian objects against attacks has obtained more and more attention, as well in war type of conditions as in "peace" time. Recent history has shown attacks in urban areas with Rocket Propelled Grenades (RPG's) and sniper guns against vehicles and humans, landmines and booby-traps against people, ground to air missiles against helicopters and airplanes, attacks with cruise missiles and gliding bombs against communication centres and power plants, ballistic missile attacks against cities, airplane attacks against populated buildings and "dynamite boat" attacks against ships, not to mention the suicide bombing events all over the world. Massive feelings of insecurity and non-safety have led to increased attention in various conferences to encounter these modern threats and the introduction of an adequate alerting sensor is the first step towards increased survivability.

Warning sensors and Infrared Search and Track systems, as described in the IR\&EO Handbook [1], form the basis for classes of sensors against first generation, classical threats against aircraft and ships. Their concepts originate from the cold war scenarios with generally long-range threats, where countermeasures consisted of the use of decoys. With the development of more hard-kill countermeasures, the need for threat identification increased. Moreover it became from a political standpoint unacceptable to kill the wrong target (for example a friend). Another aspect appeared with the introduction of urban scenarios, implying short range attacks (forcing a rapid reaction), possibly from high buildings, leading to the requirement of a large FOR. Also the need for "Situational Awareness" (SA) sensor-package, came forward. This type of sensor allows the user the determination of the locations of potential threats, to be kept into a continuous close-view. This pre-alert allows an essential gain in time and might lead to a counter-action while the weapon is on its way. The positioning of the weapon in its approach phase is essentially a 3-D issue. Some recent countermeasures like the Russian Arena system, allow close approach up to several meters, where a radar sensor is used for range determination. More advanced countermeasures need not only range, but also direction, to be measured either by additional radars or by high speed optical cameras. Countermeasures like directed energy weapons, need very precise direction information, while range information is of less importance. Jammers need course direction information, while smokes and decoys are deployed after threat-launch detection with very crude direction information. 
It has to be mentioned that the new scenarios may imply more complex land backgrounds compared to the classical seaand sky backgrounds for ships and aircraft. This introduces problems of false alarms and may lead to increased detection thresholds. It is noted that insufficient knowledge is available in the open literature, of the signatures of the variety of threats, just mentioned, in their associated backgrounds. This statement is especially valid for daytime conditions, where the sun and clear sky with bright clouds can create heavy clutter in the [1]. As a consequence generic signatures will be taken in this paper. For the development of suitable and well-optimised alerting concepts and devices, background characteristics in various environments should be considered. One way to overcome the background radiance in the visible spectrum is the use of solar blind UV sensors, applied in various Missile Approach Warning (MAW) devices, working at a wavelength of $0.25 \mu \mathrm{m}$.

Techniques for enhancing the Field of View of an imaging system are well known for a long time. Most frequently used is the concept of the reflecting convex mirror. Problems in this concept are the presence of astigmatism and field curvature, a poor f-number and dependence of magnification with range. The last problem is a well-known issue in the back view mirror of cars. Recently Chahl [2] made an improvement on this concept, while Takeya proposed the use of a two-mirror omni-directional vision system [3], providing a more compact design. A different approach towards hemispherical viewing is the concept of the fish-eye lens, introduced decades ago, and widely available now from the major companies on the photo- and video camera market. These components generally use a strongly negative convexconcave lens at the entrance, and have a limited f- number. Companies like Applied Physics Specialties in Canada are producing also fish-eye lenses for the 3-5 $\mu \mathrm{m} \mathrm{IR} \mathrm{spectral} \mathrm{band.} \mathrm{Disadvantages} \mathrm{of} \mathrm{the} \mathrm{fish-eye} \mathrm{concept} \mathrm{are} \mathrm{the} \mathrm{complexity}$ of the design, the moderate spatial resolution and an associated moderate f-number. This latter implies a lack of thermal and geometrical resolution, in contrary of the fish-eye lenses, found in the world of animals. As a result of a process of evolution, the sensitive elements in the retina are smaller, their total number is higher and the optics is simpler than what can be made at the moment in any optical company.

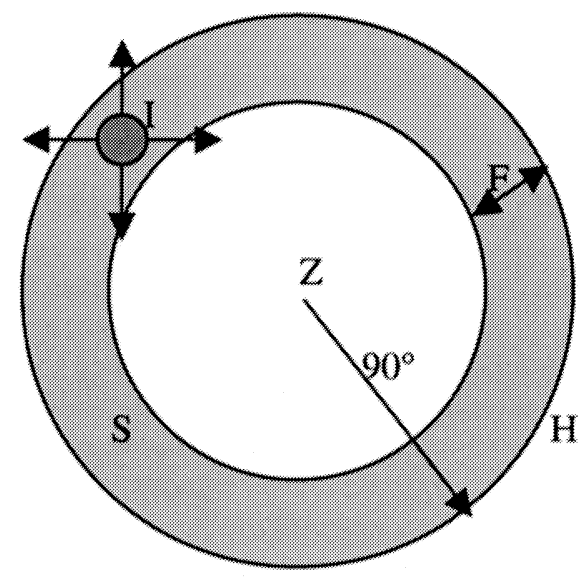

Figure 1. Principle of dual purpose sensor: Search in wide Field of Regard (FOR, S) and Identification in narrow Field of Regard (I), to be directed in any direction inside the wide FOR, using one camera with split Field of View and Focal Plane Array. $\mathrm{Z}=$ zenith, $\mathrm{H}=$ horizon, $\mathrm{F}=$ vertical Field of View

In this category of alerting sensors we have chosen at TNO-FEL for the Omni-Staring Alerting Sensor (OSAS) concept, of which the principle is similar to a design by Cook [4]. In this concept a standard mosaic detector array is observing the scene in two ways: in course resolution with the outer area of the array a wide field of view (for example panoramic) and in high resolution a small field of view with the central part of the array, of which the direction of view can be chosen in any direction of interest as depicted by the panoramically sensing part. In our concept we have chosen for a complete mirror-optical design, allowing the use multi-spectral (visual/IR) techniques. This concept is explained in more detail in section 2, while the principle is elucidated in Figure 1. In the case of the human eye, something similar occurs in the macula lutea, where the high density of the cones provides the high resolution, used for seeing details. The principle of using two different fields of view is anyway applied in many fielded cameras, either by using one detector array and two lenses, or even by using two complete independent camera systems. In this case however, the wide field of view is mostly limited to something like $40^{\circ} \times 30^{\circ}$. 
A disadvantage of the OSAS concept is the non-hemispherical field coverage. An alternative approach in this direction is the use of a multi-lens system with individual consecutive fields of view, in total covering a hemisphere, similar to what is found in the eyes of various insects. A classical example of this approach is the demonstration model developed at TNO-FEL, shown in Figure 2, where a number of staring radiometers, each having a Field of View of $20^{\circ} \times 20^{\circ}$, cover the whole hemisphere. The concept was chosen for the detection launch flashes of anti-tank missiles at ranges up- to $3 \mathrm{~km}$. The detectors chosen were Silicon $(0.9 \mu \mathrm{m})$ or Germanium $(1.5 \mu \mathrm{m})$ and the pupil diameter of each lens was $15 \mathrm{~mm}$. A problem with this concept is the presence of the sun or bright clouds inside the Field of View of a sensor, blinding it in the corresponding direction. In operational use an alarm was intended to trigger a smoke screen and manoeuvring, similar to reactions in the world of animals. It is noted that new technologies have become available such as molded and plastic optics, making the sensor heads cheaper and more robust and optical fibres, allowing a more remote and comfortable position of the detectors in relation to the lenses. A concept with more spatial resolution was developed in the early eighties by Professor Corsi from the Italian company Elettronica. In this system (CERBERO), the hemisphere was covered by means of 12 cameras, each with a Field of View of $45^{\circ} \times 45^{\circ}$ and a PbTe Focal Plane Array of $32 \times 32$ detector elements, operating in the $4 \mu \mathrm{m}$ band. One of the problems in this concept is the very complex processing in the presence of a cluttered background and moving platform.

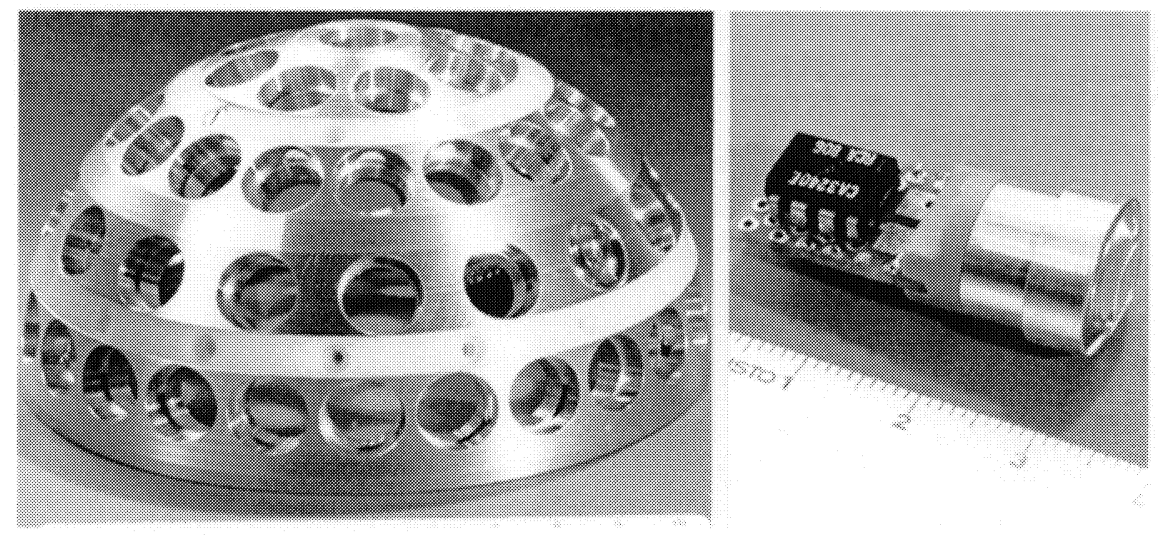

Figure 2. Example of a full stare hemispherical alerting demonstrator, working in the near IR, developed at TNO-FEL

As a kind of follow-up to this concept, a EUCLID programme RTP 8.2 started in the mid-nineties, where a number of countries tackled the technological problems just mentioned, while introducing new generations of detector arrays [5]. The sensor in this concept was to be used in land backgrounds (tanks and helicopters) as alerting device against missile attacks. One of the dual band designs out of the CUPOLA concept is shown in figure 3. A total of $2 \times 36$ Focal Plane Arrays is required, each having a Field of View of $20^{\circ} \times 20^{\circ}$, provide a total Field of View of $40^{\circ} \times 360^{\circ}$. The detector arrays have $1024 \times 1024$ respectively $512 \times 512$ elements for the mid-wave and long-wave IR bands, providing Instantaneous Fields of View of 0.34 and $0.68 \mathrm{mrad}$. The optics diameter is 6 respectively $4 \mathrm{~cm}$ and the $\mathrm{f}$-number is 1 in both cases. The required processing power is $140 \mathrm{Gflpos}$.
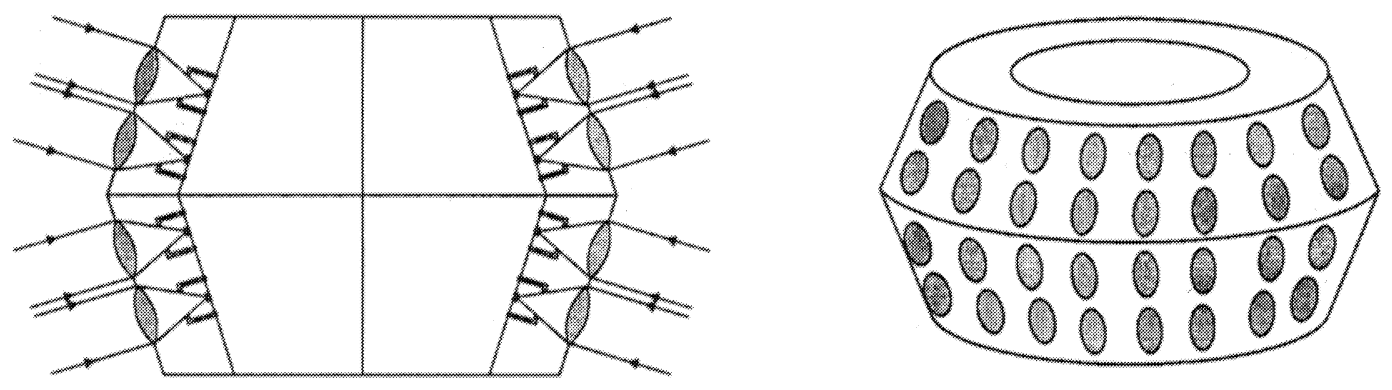

Figure 3. Principle of one of the CUPOLA concepts, dual band with $40^{\circ} \times 360^{\circ}$ 
An earlier concept for high-speed surveillance was born out of the requirement for detection of incoming missiles against tanks and aircraft. Keeping in mind the short duration of launch flashes, a high frame rate Missile Launch and Approach Detection System (MILANDES) was developed at TNO-FEL, operating in two spectral bands (Near IR and mid-wave IR) and provided with a laser retro-reflection sensor. The system used linear detector arrays, scanning a vertical Field of View of $8^{\circ}, 400$ times per second. A more detailed description of this sensor is given in section 3. Other IRST concepts were created for air defence purposes, such as ADAD in the United Kingdom, ANSAR-8 in the United States, VAMPIR in France, IRS-700 in Sweden, SPIRTAS in Israel and IRSCAN in the Netherlands, all of them based upon the use of a linear detector array, scanning the sky above the horizon up-to an angle of about 5-10 $0^{\circ}$ with an Instantaneous Field of View of about $0.5 \mathrm{mrad}$. More recently HGH (France) produced a low-cost IRST demonstrator using a $288 \times 4$ Time Delay and Integration (TDI) detector [6], similar to the SIRIUS (Thales) concept [7] with 300x8 detectors and the IRSS concept in the US [8]. The main use of these devices is as component in the defence of high value targets (ships, Air Defence sites). Simultaneously IRST concepts for use on board of fighter planes were developed, using scanning linear detector arrays, such as the FIRSTSIGHTand PIRATE systems in the UK [9,10], the OSF in France [11], the IR-OTIS system in Sweden [12] and the IRST systems for the F14 and E2C in the US.

All these latter concepts suffer from the low frame rate, which is of the order of one per second. Ideas to use twodimensional detector arrays in IRST were raised in the early nineties [13], while the detection power of infrared Focal Plane Array cameras for the detection of low flying incoming targets was demonstrated by the US HISS system [14]. The challenge is however to achieve the $360^{\circ}$ horizontal Field of View while maintaining the high frame rate, a high spatial resolution and a large vertical Field of View. One possibility is the use of anamorphic optics, enlarging the horizontal Instantaneous Field of View of each pixel. A consequence of this concept is the increase of the Noise Equivalent Irradiance (NEI) and a decrease of the sensitivity. Another possibility is the use of the step-stare concept, in which the Field of View of a camera is rapidly switched from one direction to another. One example is the concept from Bernard [15], where a micro-mirror (or lens) array is used for switching; this concept is culminating in the PIMAWS missile warning system from BGT. In this case one can make use of the increased frame rates up-to $100 \mathrm{~Hz}$ and more, such as possible in modern Focal Plane Array cameras, to keep the total Field of View frame rate acceptable (eg $>5 \mathrm{~Hz})$. Another step-stare concept uses a standard Focal Plane Array camera, running at 50 frames per second and rotating with a constant speed along the horizon, while an additional counter-rotating scan mirror keeps the direction of view (subframe) constant during the stare time of the Focal Plane Array. It is noted however, that the gain in total frame rate is marginal if the horizontal Field of View of the camera (sub-frame) is about $8^{\circ}$.

A real step forward towards the development of full stare IRST's was the study within the EUCLID programme, earlier mentioned and the start of the Staring Infrared Panoramic Sensor (SIRPS) programme as described by Buss [16]. In this programme the concept of triplex optics was investigated, splitting the Field of View of a camera into three parts, each looking in a different direction and providing a factor three reduction in the number of Focal Plane Arrays. Another boost was the development of large Focal Plane Arrays with up-to $1024^{2}$ detector elements. Finally the use of multi-band cameras was introduced, allowing the use of spectral discrimination of targets in cluttered backgrounds. The issue of false alarms and contrast reduction in certain environmental conditions is the main reason for the slow process of IR alerting systems in the armed forces [17]. Full stare IRST's allow the use of high speed multi-target trackers to tackle the problem of bird alarms, as was illustrated by research at TNO-FEL [18]. Another way to tackle the false alarm problem is the use of an additional laser system, allowing the measurement of the range to an early-detected target by means of a rapid laser-aiming device, as discussed by Schimitschek [19]. In a maritime environment, experiments show [20] that clutter problems may increase near or at the horizon, when sun-radiation is specularly reflected by waves. On the other hand atmospheric refraction may enhance the probability of detection in cases of sub-refraction, as shown by various experiments [21]. In this last reference a full stare IRST concept ARGUS (All-Round Guarding and Unveiling Sensor) has been introduced by TNO-FEL, using split-step-stare optics, giving a single camera four directions of view. This concept is further described in section 4 .

Finally an important alerting device to be mentioned is the Laser Warning Receiver (LWR), operational in several nations. A good LWR is capable to discriminate between the different laser threats such as range finders, target designators and laser beam riders. It has to be kept in mind that many lasers are working at eye-safe wavelengths, so a modern sensor should give at least a warning at the laser wavelengths: $0.699 \mu \mathrm{m}, 0.9 \mu \mathrm{m}, 1.06 \mu \mathrm{m}, 1.53 \mu \mathrm{m}, 2.06 \mu \mathrm{m}$ and $10.6 \mu \mathrm{m}$. Furthermore the angular accuracy has to be high in view of the countermeasure to be taken. One example of a modern LWR system is the HARLID ${ }^{\mathrm{TM}}$, developed in Canada [22]. 


\section{THE OSAS CONCEPT (Omni-Staring Alerting Sensor)}

In the OSAS concept, the starting point is the splitting of an intermediate image of $12.5 \times 12.5 \mathrm{~mm}$, occurring in the reimaged detector array of the Thermacam PM395 PtSi camera from Inframetrics. From this area, an outer ring of $2 \mathrm{~mm}$ diameter (corresponding to 40 detectors) is used to observe a total vertical Field of View of $7.5^{\circ}$ around the horizon, which is to be used for the alerting task. The inner area of $8.5 \mathrm{~mm}$ is used for standard imaging, in our case with the $8^{\circ}$ lens, of which $5.4^{\circ}$ is used for the identification task (see Figure 4).
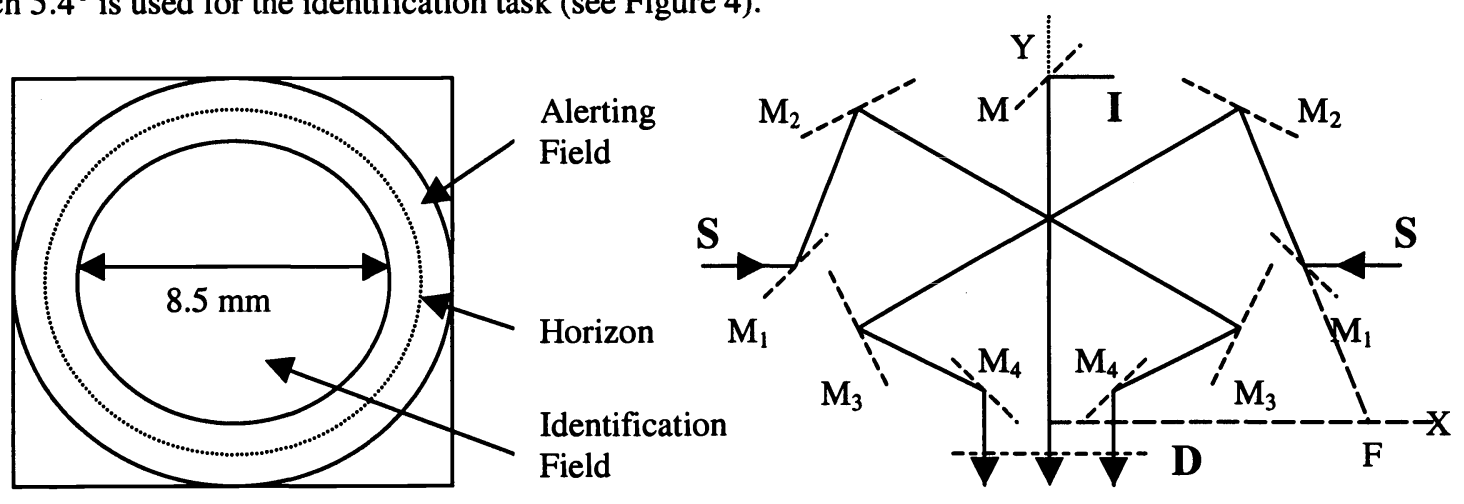

Figure 4. Principle of OSAS; left the area used for alerting and identification; right the beam splitting in the re-imaging Plane D, and the way how the search beams $S$ and the identification beam $I$ follow a set of reflecting mirror surfaces: $\mathbf{M}_{1}$ is a paraboloid; $\mathbf{M}_{2}$ is an ellipsoid; $\mathbf{M}_{3}$ is a hyperboloid; $\mathbf{M}_{4}$ is a conical mirror, all symmetrical around the $\mathrm{Y}$-axis. Mirror $\mathrm{M}$, rotating around the $\mathrm{Y}$-axis, reflects the identification beam. $\mathrm{F}$ is the focus of the paraboloid and the ellipsoid and is located on the $\mathrm{X}$-axis

The imaging system is using a set of reflecting quadratic surfaces in order to focus the panoramic search field onto the reimaging plane D. Mirror $\mathbf{M}_{1}$ is a paraboloid, having its focus in the meridional plane (plane of the drawing) at the same place as the ellipsoidal mirror $\mathrm{M}_{2}$. The second focus of this ellipsoid is at the same place as that of the hyperboloid $\mathrm{M}_{3}$. The second focus of M3 is just at the surface of the conical mirror M4. In the sagittal plane the imaging is quite different, as the focal lengths of the reflecting surfaces are different from the meridional case, but the curvatures are chosen in such a way, that the focal planes are the same. The difference is the apparent focal lengths: $15.20 \mathrm{~mm}$ for the meridional beams and $5.25 \mathrm{~mm}$ for the sagittal beams. The equations for the reflecting surfaces in the meridional plane are:

$$
\begin{aligned}
& \text { Paraboloid } \\
& \text { Ellipsoid } \quad \frac{[(y-u) \sin \mu+(x-t) \cos \mu]^{2}}{56.63^{2}}+\frac{[(y-u) \cos \mu-(x-t) \sin \mu]^{2}}{47.14^{2}}=1 \\
& \text { Hyperboloid } \quad \frac{[(y-z) \sin v+(x-w) \cos v]^{2}}{6.65^{2}}+\frac{[(y-z) \cos v-(x-w) \sin v]^{2}}{9.73^{2}}=1
\end{aligned}
$$

In these formulae $\mathrm{t}=4.805, \mathrm{u}=4.465, \mathrm{w}=-15.76$ and $\mathrm{z}=-3.61$; all dimensions are given in $\mathrm{mm}$. De angles and, having values of $8.179^{\circ}$ respectively $26.88^{\circ}$, denote the angles of rotation of the main axis of the ellipsoid respectively the hyperboloid. The radii of the circles through the intersection of the central part of the beam and the paraboloid, ellipsoid and hyperboloid are $29.35 \mathrm{~mm}, 25.00 \mathrm{~mm}$ respectively $11.50 \mathrm{~mm}$. It is noted, that the aberration in the search field are only reduced for the axial rays In the outer part of the vertical field of view and for the outer part of the beam in horizontal direction, the blur spot increases considerably, mainly due to the small radius of curvature of the hyperboloid and the conical mirror. The instantaneous Field of View of one detector becomes $3.3 \times 9.5 \mathrm{mrad}(\mathrm{VxH})$. It is noted that below the mirror $\mathrm{M}$ in figure 4, the standard front-lens of the Thermacam is positioned, giving a standard image for the central part of the Focal Plane Array. It is also noted that some vignetting occurs at the entrance of the conical mirror $\mathbf{M}_{\mathbf{4}}$, especially when the full aperture is used. 
The use of a mirror optical system allows the use of infrared as well as daylight cameras. Besides the Thermacam infrared camera we have used a Philips CCD camera with a chip size of $6.4 \times 4.8 \mathrm{~mm}$. This chip was re-imaged onto the conical reflector by means of two standard NIKON lenses with focal lengths of 35 and $85 \mathrm{~mm}$. For the front-lens a standard $80 \mathrm{~mm}$ achromatic doublet was chosen. An example of an image, taken with this set-up out of the window, is shown in Figure 5. The picture shows a parking place and the close-up of one car, moving through the identification field. The picture does not show the dark part of the image of the inside of the room.

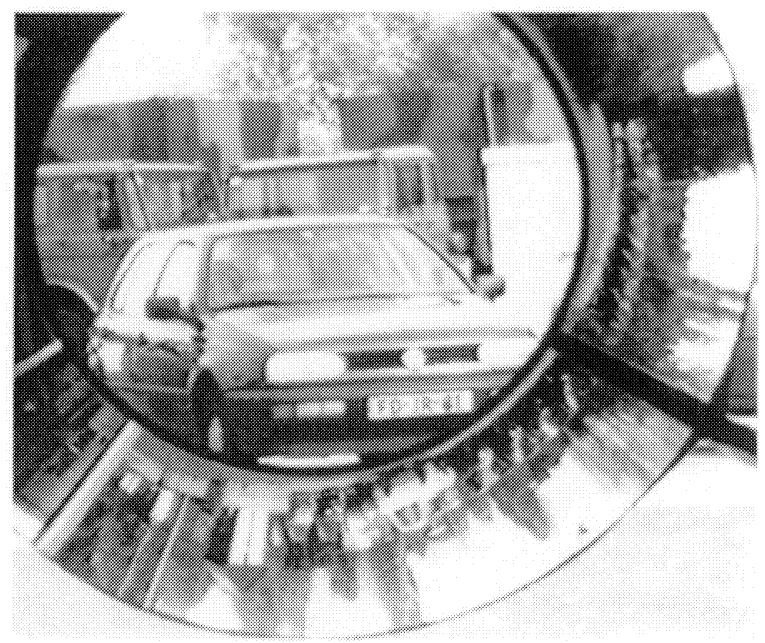

Figure 5. Image taken with the OSAS system, provided with a daylight CCD camera

Tests, carried out with the Thermacam showed similar results. Any motion in the outer search field was easily detected and located. Target recognition in this field was problematic due to the low spatial resolution. The resolution in the identification field was the same as the standard Thermacam camera provides.

\section{THE MILANDES CONCEPT (MIssile Launch AND approach DEtection System)}

In order to obtain at least 4 signal pulses on the flash from the launch of a typical anti-tank missile, an optical scanning system was designed, providing 400 scans per second for the whole 360 degrees around. It was decided to introduce a dual waveband optical/IR sensor, consisting of linear detector arrays with 16 elements each, which is a standard type of commercially available product. The choice of the spectral bands was made on the basis of predictions of the ratio of the radiance of a $2000^{\circ} \mathrm{K}$ target type source and the daytime background. Keeping in mind the availability of detector arrays and their affordability (in cost), the choice was made for Silicon in the $0.7-1.0 \mu \mathrm{m}$ band and two stage Peltier cooled Lead Selenide in the $3.4-4.1 \mu \mathrm{m}$ band. The peak detectivity $\mathrm{D}^{*}$ (peak) of these arrays is approximately $2.5 \times 10^{10}$ resp $1.5 \times 10^{10} \mathrm{cmHz}^{1 / 2} \mathrm{Watt}^{-1}$.

In our design a vertical Field of View of $8^{\circ}$ was chosen, while each optical system had an entrance pupil diameter of about $20 \mathrm{~mm}$. Given the size of the detector elements (pitches of 200 respectively $150 \mu \mathrm{m}$ for the $\mathrm{Si}$ and PbSe detectors) the focal lengths were designed to be 23.25 respectively $17.22 \mathrm{~mm}$. This was achieved by chosing a three element aplanatic design for the Si detectors (material SF10) and a two element aplanatic design for the PbSe detectors (material Silicon). All surfaces were provided with single layer anti-reflection coatings for wavelengths of $0.85 \mu \mathrm{m}$ respectively $3.8 \mu \mathrm{m}$. In order to reduce the size of the scanning mirror set, it was decided to use a dichroic beam splitter, transmitting the $\mathrm{PbSe}$ band and reflecting the $\mathrm{Si}$ band. This beam splitter was built up on a substrate of Irtran I material and consisted of 9 quarter-wave layers of $\mathrm{ZnS}$ and $\mathrm{MgF}_{2}$ material. Provisions were made to split-up the near IR band one more time in order to incorporate a detection channel for reflected laser light, working at a wavelength of $0.906 \mu \mathrm{m}$. This laser system supports the false alarm reduction and is capable to provide range information, which is important when using countermeasures such as smokes or decoys. Furthermore the laser retro reflected signal may contain information on the type of seeker-head, present in the approaching threat. 
Figure 6 presents the optical principle of the design. The 6-sided scan-drum is driven with a motor running at a rotation speed of $3000 \mathrm{rpm}$. In the design illustrated, just one vertical scan angle is shown, scanning $4^{\circ}$ above and below the horizon. If the scan mirrors have more than just one angle, a multi-angle scan can be obtained, providing a larger vertical Field of View, but at a lower frame rate. The Field of View is simultaneously scanned by a laser detector, which receives the retro-reflections by the target from the laser radiation, emitted by the laser diode array, which simultaneously sweeps the same Field of View. A set of beam splitters separates the incoming beams to the dedicated detectors. The protecting window material was Calcium Aluminate, transparent in both visual and IR.

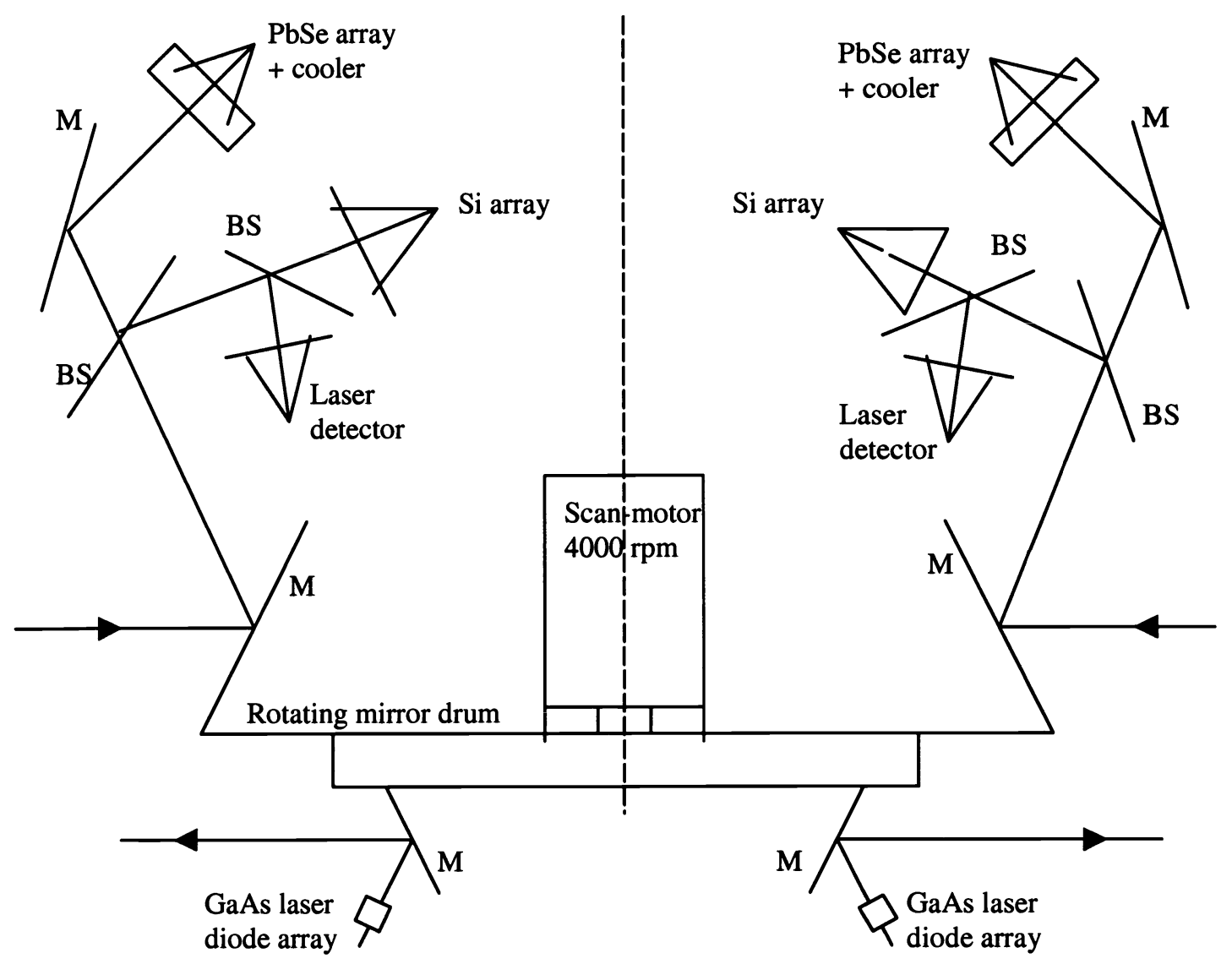

Figure 6. Schematic principle of the MILANDES set-up; $M$ are mirrors, BS are dichroic beam splitters

An experimental set-up according to the scheme in Figure 6 was extensively tested from a tower at TNO-FEL. The infrared sensitivity was found to be according to the expected NEI value of the PbSe channel: $50 \mathrm{pWatt} / \mathrm{cm}^{2}$. An event with a radiant intensity contrast of $200 \mathrm{Watt} / \mathrm{sr}$ can easily be detected at a distance of $5 \mathrm{~km}$, even when the atmospheric transmission is about $30 \%$ over that range. The laser system was tested with realistic optical heads. It was found that for a given visibility of $5 \mathrm{~km}$, a laser peak power of 50 Watt, a retro-reflection coefficient of 0.1 and a detector with a Noise Equivalent Power of $0.05 \mathrm{pWatt} / \mathrm{Hz}^{1 / 2}$ was enough to obtain a signal to noise ratio of 3 at a range of $3 \mathrm{~km}$. The major issue in the scanning concept of MILANDES was found to be the land-background clutter. As can be seen in Figure 7, daytime conditions provide strong signal variations in both spectral bands. One reason is the high sensitivity; because of the large Instantaneous Field of View of about $8 \mathrm{mrad}$ and the high f-number, the Noise Equivalent Temperature Difference in the infrared channel is of the order of $10 \mathrm{mK}$. Also the visual channel provides a good signal to noise ratio even in light level conditions of $50 \mathrm{Watt} / \mathrm{m}^{2}$. As the signal amplifiers are AC coupled, the principle of taking the ratio of the signals in both channels did not work properly, especially in daytime. For night-time conditions the problems were less severe, as in this case the near infrared channel only shows the target pulse. The lesson learned from the experiments was that a higher spatial resolution is required and that DC coupled electronics are highly preferable. Furthermore the scanning system is giving problems when used on a moving platform, resulting in complex correction processing algorithms. 


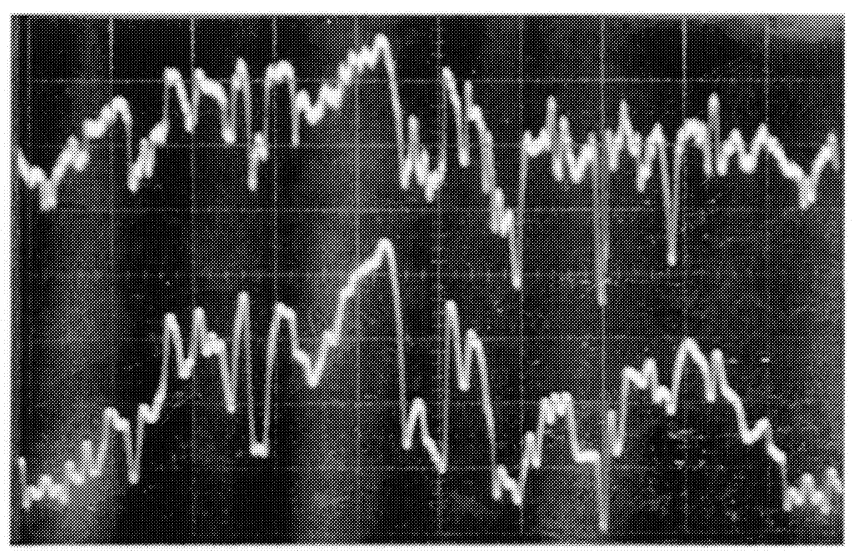

Figure 7. Example of two-channel signal recordings from MILANDES, taken in a typical daytime land background; upper signal: $\mathrm{Si}$, lower signal: $\mathrm{PbSe}$

\section{THE ARGUS CONCEPT (All-Round Guarding and Unveiling Sensor)}

This concept concerns the use of a set of cameras, fully staring around. This would imply the use of 48 cameras to cover the whole panoramic view of $360^{\circ}$, each having a horizontal Field of View of at least $7.5^{\circ}$. It is clear that a reduction of the number of cameras is highly recommended to reduce the cost, especially in the case that thermal IR cameras are used or even the use of a combined mid-wave/long-wave IR system is considered. We have investigated the principle of splitting the vertical Field of View of a camera into the upper and lower part and to separate the even and odd frames. In this way we obtain four directions of view, as illustrated in Figure 8. For the original camera Field of view we have chosen $8^{\circ} \times 6^{\circ}$, so the splitted image has a Field of View of $32^{\circ} \times 3^{\circ}$. We allow an overlap of $0.5^{\circ}$ between the consecutive fields, so our single combined field ends up with $30^{\circ} \times 3^{\circ}$, which is imaged at a frame rate of $25 \mathrm{~Hz}$.

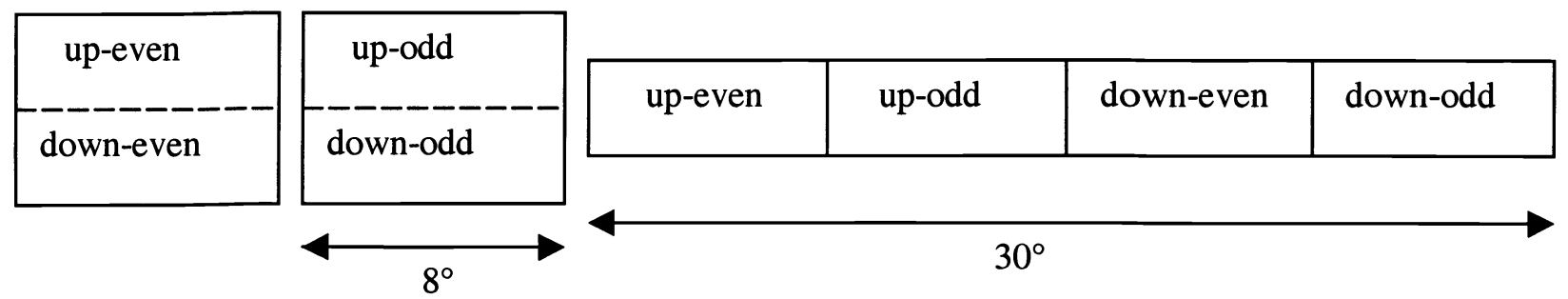

Figure 8. Principle of splitting the Field of View of a single camera into four directions of view

The beam splitting is done in the plane, where the detector array is re-imaged. The splitting element is a roof mirror, which can rotate within certain limits around the roof edge. The roof edge is horizontally oriented and splits the image into two parts of equal size; one part is reflected upward, the other part is reflected downward. By tilting the roof mirror in two dedicated positions, the upward and downward beams are successively following two different optical chains, each consisting of three mirrors and one front-lens. Two of the mirrors are adjustable in order to direct the beams into the appropriate directions. In order to avoid vignetting, a field lens is used in front of the roof edge, imaging the entrance pupil onto the re-imaging lens. For demonstration purposes an experimental system was set-up, using a standard CCD camera and lenses for the visual band. In our case we used a Philips CCD camera, type LDH 0703 with a chip size of $6.4 \times 4.8 \mathrm{~mm}$, and used $35 \mathrm{~mm}$ and $50 \mathrm{~mm}$ Nikon lenses for re-imaging the chip on the roof edge via the field lens to an image with size: $8.3 \times 6.3 \mathrm{~mm}$. The front-lenses have a focal length of $100 \mathrm{~mm}$. The Field of View of one split image is $4.75^{\circ} \times 1.8^{\circ}$, while the combined Field of View is $18^{\circ} \times 1.8^{\circ}$. An example of an image, obtained with this set-up, is shown in Figure 9. The picture shows a view of part of the skyline of The Hague. 


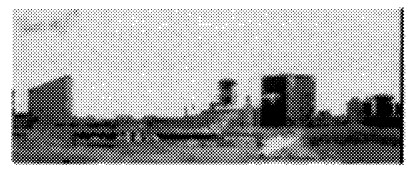

Up-even

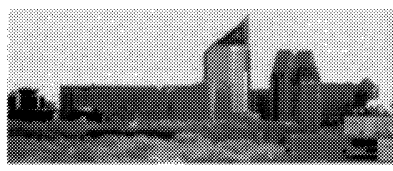

Up-odd

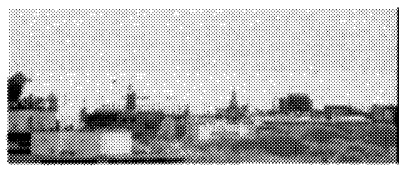

Down-even

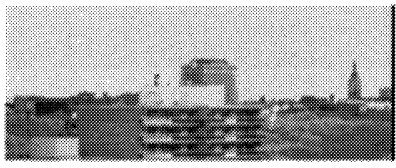

Down-odd

Figure 9. View of the skyline of The Hague, taken with the optical ARGUS demonstrator

It is evident that the full stare concept provides big advantages over the scanning concept, because even in a cluttered background, any motion or signal variation is easily observed by simply comparing (subtracting) consecutive frames. Modern IR cameras provide day and night capability with a spatial resolution, allowing not only detection but also a good deal of recognition and identification, especially when super-resolution algorithms can be applied. This is the case when an undersampled, non-diffraction limited camera with optics with a Point Spread Function smaller than the Instantaneous Field of View, is allowed to pan slowly over the scene. Thanks to the high frame rate, more data can be plotted in the track table, and even with large numbers of false alarms, most of them are eliminated after perception of the plot track during some time.

The optical principle of ARGUS allows not only surveillance of targets just above or below the horizon. By mounting the whole optical unit on a steerable platform, the vertical Field of View of $3^{\circ}$ can easily be directed towards higher elevations, which might be required in the case of high-angle attack. One and the same system can detect targets below the horizon, such as small rubber boats, people in the water and so on, but also air targets like gliding bombs and UCAV's. Similar to [21] and [23], a system following the ARGUS concept is under consideration, to be applied on high value targets like warships, communication centres and air defence sites. The sensors, scheduled at this moment in the system are standard available mid-wave and long-wave IR cameras. Their characteristics and performances, as valid for the non-splitted optics with a numerical aperture of $\mathrm{f} / 2.5$, are listed in Table 1 . Range predictions are given for three generic types of target in standard atmospheric conditions with extinction coefficients of 0.1 respectively $0.2 \mathrm{~km}^{-1}$ for the mid-wave and long-wave spectral band. The detection threshold is taken at three times the Noise Equivalent Irradiance level. The targets are typical and up to date: a solid fuel (SF) subsonic missile, an air breathing incoming cruise missile, a

Table 1. Characteristics and performances of a generic ARGUS mid-wave and long-wave sensor

\begin{tabular}{|c|c|c|c|}
\hline \multicolumn{2}{|c|}{ parameter } & mid-wave & long-wave \\
\hline \multicolumn{2}{|c|}{ detector material } & $\mathrm{HgCdTe}$ & GaAs:AlGaAs \\
\hline \multicolumn{2}{|c|}{ spectral band } & $3.6-4.2 \mu \mathrm{m}$ & $8-9 \mu \mathrm{m}$ \\
\hline \multicolumn{2}{|c|}{ number of detectors } & $640 \times 512$ & $640 \times 512$ \\
\hline \multicolumn{2}{|c|}{ Field of View } & $8^{\circ} \times 6^{\circ}$ & $8^{\circ} \times 6^{\circ}$ \\
\hline \multicolumn{2}{|c|}{ Instant. Field of View } & $0.218 \mathrm{mrad}$ & $0.218 \mathrm{mrad}$ \\
\hline \multicolumn{2}{|c|}{ focal length } & $110 \mathrm{~mm}$ & $110 \mathrm{~mm}$ \\
\hline \multicolumn{2}{|l|}{ NETD } & $20 \mathrm{mK}$ & $10 \mathrm{mK}$ \\
\hline \multicolumn{2}{|l|}{ NEI } & $9 \mathrm{pWatt} / \mathrm{m}^{2}$ & $70 \mathrm{pWat} / \mathrm{m}^{2}$ \\
\hline \multirow{4}{*}{$\begin{array}{l}\text { Detec- } \\
\text { tion } \\
\text { Range }\end{array}$} & SF Missile & $50 \mathrm{~km}$ & $22.7 \mathrm{~km}$ \\
\hline & Air breather & $21 \mathrm{~km}$ & $17.3 \mathrm{~km}$ \\
\hline & Rubber boat & $13.7 \mathrm{~km}$ & $10.6 \mathrm{~km}$ \\
\hline & Swimmer & $4.8 \mathrm{~km}$ & $4.4 \mathrm{~km}$ \\
\hline
\end{tabular}


small rubber boat, such as might be used against ships in surface attacks and the head of a swimmer, being a target to be rescued. The scenario concerns a clear sky condition with low wind speed $(<5 \mathrm{~m} / \mathrm{s})$ and sea-state $(<2)$. For the radiant intensity contrasts of these targets, we have taken the values $10000,100,20$ respectively $1 \mathrm{mWatt} / \mathrm{sr}$ in the mid-wave and $10000,2000,200$ and $10 \mathrm{mWatt} / \mathrm{sr}$ in the long-wave spectral band. In the case of ship-platform, the sensor is assumed to be located at a height of about $15 \mathrm{~m}$ above sea level.

The table shows the power of full stare IR systems, taking advantage of the high full-frame rate and the associated capabilities of advanced processors, including track before detect and multi-target tracking. Even for pupil irradiance values of three times the NEI level, first detection can take place. The system described allows early detection of dim targets in a large Field of View. Moreover, it is evident that the high spatial resolution, with Minimum Resolvable Temperature Difference (MRTD) curves going up-to a high frequency limit of about 4 cycles/mrad, allows attractive recognition and identification performance. The NATO-standard target of $2.3 \times 2.3 \mathrm{~m}$ and a temperature difference of two degrees can be recognized with a $50 \%$ probability at a range of $3100 \mathrm{~m}$.

\section{DISCUSSION, COMPARISON OF CONCEPTS}

The various concepts of panoramic alerting sensors (including Laser Warning Receiver LWR and UV Missile Approach Warner (MAW)), considered in this paper, are briefly summarized in Table 2. Indications are givenof their main potential application, the threat that they are intended to detect (including surface to air missile (SAM), air to air missile (AAM) or tactical ballistic missile (TBM)), the Field of View (FOV), their complexity (cost), advantages and drawbacks.

Table 2. Comparison of concepts of panoramic alerting devices

\begin{tabular}{|l|l|l|l|l|l|l|}
\hline Sensor concept & \multicolumn{1}{|c|}{ Application } & \multicolumn{1}{|c|}{ Threat } & FOV & $\begin{array}{l}\text { Complexity } \\
\text { Cost }\end{array}$ & \multicolumn{1}{|c|}{ Advantages } & \multicolumn{1}{|c|}{ Drawbacks } \\
\hline LWR & $\begin{array}{l}\text { tank, } \\
\text { helicopter }\end{array}$ & $\begin{array}{l}\text { beam rider, } \\
\text { designator }\end{array}$ & $2 \pi$ & low & small, reliable & $\begin{array}{l}\text { multiple } \\
\text { wavelengths }\end{array}$ \\
\hline UV-MAW & $\begin{array}{l}\text { jet plane, } \\
\text { helicopter }\end{array}$ & SAM, AAM & $2 \pi$ & moderate & $\begin{array}{l}\text { small, } \\
\text { solar blind }\end{array}$ & poor in haze \\
\hline $1^{\text {st }}$ gen IRST & warship & anti ship missile & $\begin{array}{l}360^{\circ} \mathrm{x} \\
10^{\circ}\end{array}$ & $\begin{array}{l}\text { moderate to } \\
\text { high }\end{array}$ & $\begin{array}{l}\text { good situatio- } \\
\text { nal awareness }\end{array}$ & $\begin{array}{l}\text { high false } \\
\text { alarm rate }\end{array}$ \\
\hline $2^{\text {nd }}$ gen IRST & $\begin{array}{l}\text { warship, jet } \\
\text { plane, AD site }\end{array}$ & $\begin{array}{l}\text { anti ship missile, } \\
\text { TBM }\end{array}$ & $\begin{array}{l}360^{\circ} \mathrm{x} \\
4^{\circ}\end{array}$ & $\begin{array}{l}\text { moderate to } \\
\text { high }\end{array}$ & sensitive & false alarms \\
\hline CERBERO & $\begin{array}{l}\text { tank, } \\
\text { helicopter }\end{array}$ & $\begin{array}{l}\text { SAM, anti tank } \\
\text { missile }\end{array}$ & $2 \pi$ & $\begin{array}{l}\text { moderate to } \\
\text { high }\end{array}$ & less cameras & $\begin{array}{l}\text { low spatial } \\
\text { resolution }\end{array}$ \\
\hline $\begin{array}{l}\text { Step-stare IRST } \\
\text { PIMAWS }\end{array}$ & $\begin{array}{l}\text { AD site, } \\
\text { jet plane }\end{array}$ & $\begin{array}{l}\text { AAM, air to } \\
\text { surface missile }\end{array}$ & $2 \pi$ & high & $\begin{array}{l}\text { less cameras } \\
\text { high frame rate }\end{array}$ & $\begin{array}{l}\text { complex } \\
\text { optics }\end{array}$ \\
\hline CUPOLA & $\begin{array}{l}\text { tank } \\
\text { helicopter }\end{array}$ & $\begin{array}{l}\text { SAM, anti tank } \\
\text { missile }\end{array}$ & $\begin{array}{l}360^{\circ} \mathrm{x} \\
40^{\circ}\end{array}$ & very high & large FOV & many cameras \\
\hline OSAS & tank & anti tank missile & $\begin{array}{l}360^{\circ} \mathrm{x} \\
7.5^{\circ}\end{array}$ & low & $\begin{array}{l}\text { one camera, } \\
\text { dual purpose }\end{array}$ & $\begin{array}{l}\text { low spatial } \\
\text { resolution }\end{array}$ \\
\hline MILANDES & helicopter & SAM, AAM & $\begin{array}{l}360^{\circ} \mathrm{x} \\
8^{\circ}\end{array}$ & $\begin{array}{l}\text { moderate to } \\
\text { high }\end{array}$ & laser ranging & $\begin{array}{l}\text { low resolution } \\
\text { high FA rate }\end{array}$ \\
\hline ARGUS & $\begin{array}{l}\text { AD site, } \\
\text { warship }\end{array}$ & $\begin{array}{l}\text { anti ship missile, } \\
\text { surface threat }\end{array}$ & $\begin{array}{l}360^{\circ} \mathrm{x} \\
3^{\circ}\end{array}$ & very high & $\begin{array}{l}\text { sensitive, low } \\
\text { FA rate }\end{array}$ & $\begin{array}{l}\text { small vertical } \\
\text { FOV }\end{array}$ \\
\hline
\end{tabular}

The table is indicative for the capabilities of the various concepts. The user often has to deal with a limited amount of funds available and therefore has to live with a cheaper device with less performance. In other cases available space is a driving factor, such as in the EFA airplane, reason why a scanning concept is preferred. In the case of high value objects, like big warships, an expensive concept with cooled cameras can be afforded. A small warship, requiring less range against surface targets, might use a full stare concept with uncooled cameras with larger FOV and less spatial resolution. 


\section{REFERENCES}

[1] The Infrared and Electro-Optics Systems Handbook; Volume 5: Passive Electro-Optical Systems, Volume 7: Countermeasures, Volume 2: Sources of Radiation; SPIE Optical Engineering Press, 1993.

[2] J.S. Chahl et al, Reflective surfaces for panoramic imaging, Applied Optics, Volume 36, No. 31, pp 8275-8285, 1 November 1997

[3] A. Takeya et al, Omni-directional vision system using two mirrors, Proc. SPIE, Volume 3430, San Diego, July 1998

[4] Lacy G. Cook, Integrated panoramic and high-resolution sensor optics, European Patent Application 971096630.0, filed 13 June 1997

[5] S. Landini et al, EUCLID RTP 8.2 IRST software simulator, SPIE Volume 3436, Infrared Technology and Applications XXIV, San Diego, July 1998

[6] G. Gaussorgues et al, Low cost shipborne passive infrared search and track, SPIE Volume 4130, Infrared Technology and Applications XXVI, San Diego, July/August 2000

[7] Rango Knepper, SIRIUS, a long range IRST system, SPIE Volume 3061, Infrared Technology and Applications XXIII, Orlando, April 1997

[8] George Ax et al, Navy EO sensor testbed development for IRST, SPIE Volume 2552, Infrared Technology and Applications XXI, Orlando, April 1995

[9] Greg A. Page, Long-range target detection algorithms for Infrared Search and Track, SPIE Volume 3698, Infrared Technology and Applications XXV, Orlando, April 1999

[10] Boyd Cook, Pirate: the IRST for Eurofighter Typhoon, SPIE Volume 4820, Infrared Technology and Applications XXVIII, Seattle, July 2002

[11] Jean-Michel Missirian et al, IRST: a key system in modern warfare, SPIE Volume 3061, Infrared Technology and Applications XXIII, Orlando, April 1997

[12] I. Anderson et al, SAAB IRST: the system and flight trials, SPIE Volume 4820, Infrared Technology and Applications XXVIII, Seattle, July 2002

[13] Arie N. de Jong et al, Advanced IRST systems, Proceedings AGARD-GCP 57th Symposium on Pointing and Tracking Systems, Seattle, October 1993

[14] Robert Headley et al, Horizon Infrared Surveillance Sensor (HISS), SPIE Volume 2552, Infrared Technology and Applications XXI, Orlando, April 1995

[15] Walter Bernard, Technology demonstrator for ground-based surveillance and missile warning, SPIE Volume 3436, Infrared Technology and Applications XXIV, San Diego, July 1998

[16] James Buss, Staring Infrared Panoramic Sensor (SIRPS), SPIE Volume 3436, Infrared Technology and Applications XXIV, San Diego, July 1998

[17] Arie N. de Jong, IRST and its perspective, SPIE Volume 2552, Infrared Technology and Applications XXI, San Diego, July 1995

[18] Arie N. de Jong et al, Encountering bird alarms in full stare IRST's, SPIE Volume 4130, Infrared Technology and Applications XXVI, San Diego, July/August 2000

[19] E. Schimitschek et al, Integration of an eye-safe solid state laser radar with an IRST, Proceedings $2^{\text {nd }}$ NATO-IRIS Symposium, Paris, London, June 1996

[20] Arie N. de Jong et al, TG16 point target detection experiment POLLEX, Livorno 2001, SPIE Volume 4820, Infrared Technology and Applications XXVIII, Seattle, July 2002

[21] Arie N. de Jong et al, Enhanced IR point target detection by atmospheric effects, SPIE Volume 4820, Infrared Technology and Applications XXVIII, Seattle, July 2002

[22] Paul Webb et al, Improved miniaturized HARLID ${ }^{T M}$ for laser warning systems having high angular resolution, SPIE Volume 4369, Infrared Technology and Applications XXVII, Orlando, April 2001

[23] Arie N. de Jong et al, IR detection of very small invading surface and sub-surface targets in littoral waters, Proceedings $5^{\text {th }}$ MSS NATO-IRIS symposium, Gaithersburg, December 2002 